\title{
ESBOÇO DE UMA HISTÓRIA SOCIAL DA PRIMEIRA GERAÇÃO DE SOCIÓLOGOS DO TRABALHO E DOS TRABALHADORES NO BRASIL*
}

\author{
JosÉ SERgio LeITE LOPES** \\ ELINA PeSSANHA ${ }^{* * *}$ \\ JosÉ RICARDO RAMALHO ${ }^{* * * *}$
}

\begin{abstract}
RESUMO: $\mathrm{O}$ artigo anuncia as questões que guiam a pesquisa em desenvolvimento e que podem ser assim resumidas: as relações individuais dos primeiros sociólogos do trabalho com os grupos hegemônicos dentro da sociologia universitária; sua integração nos outros institutos ou departamentos aos quais a sociologia oferecia seus quadros; a incidência de sanções políticas que tiveram o efeito de interromper ou de desviar suas carreiras; as probabilidades de exposição à circulação internacional das ideias, através dos deslocamentos pessoais ao exterior ou por seu pertencimento a redes internacionais; assim como também sua exposição diferencial à circulação das ideias entre as classes sociais, em particular com relação ao seu próprio objeto de estudo: a classe trabalhadora.
\end{abstract}

Palavras-chave: A universidade e o tema do trabalho no Brasil. Sociologia da Sociologia. História social de uma geração de sociólogos do trabalho. Etnografia reflexiva dos estudiosos dos trabalhadores.

* Este artigo retoma a exposição feita por José Sergio Leite Lopes sob o título de "Constituição e desenvolvimento da Sociologia do Trabalho no Brasil", na mesa "A Sociologia do Trabalho como campo de pesquisa - a constituição da Sociologia do Trabalho no Brasil", no seminário "Quando a sociologia se submete à análise sociológica", organizado pelo Doutorado em Ciências Sociais, realizado na Faculdade de Educação da Universidade Estadual de Campinas (Unicamp), em 24 de outubro de 2011. Ele retoma os termos do projeto de pesquisa coordenado por José Sergio, Elina Pessanha e José Ricardo Ramalho, e que conta com as colaborações de Regina Morel e Marco Aurélio Santana (IFCS-UFRJ), Heloísa Martins e Iram Rodrigues (USP) e Marco Antonio Peruzzo (UFRRJ). Tal projeto de pesquisa tomou a dimensão de trabalho de equipe desde 2004, recuperando um antigo projeto individual inconcluso de Leite Lopes iniciado em 1991.

** Doutor em Antropologia Social e professor titular do Museu Nacional, da Universidade Federal do Rio de Janeiro (UFRJ). E-mail: jsergiollopes@gmail.com

*** Doutora em Ciências Humanas e professora associada do Programa de Pós-Graduação em Sociologia e Antropologia, do Instituto de Filosofia e Ciências Sociais (IFCS) da UFRJ. E-mail: elina.pessanha@terra.com.br

**** Doutor em Ciências Sociais e professor titular do Programa de Pós-Graduação em Sociologia e Antropologia do IFCS/ UFRJ. E-mail: jramalho@ifcs.ufrj.br 


\title{
OUTLINE OF A SOCIAL HISTORY OF FIRST GENERATION OF LABOR SOCIOLOGISTS AND BRAZILIAN EMPLOYEES
}

\begin{abstract}
This paper announces the questions that guide the research in development that can be summarized as follows: the individual relationships of the first labor sociologists with the hegemonic groups inside university sociology; their integration into other institutes or departments where sociology offered its staff; the existence of political sanctions that interrupted or deviated their carriers; the probabilities of their exposure to the international circulation of ideas, by means of personal trips abroad or their involvement into international networks; and also their different exposure to the circulation of ideas among and between social classes, particularly in relation to their own research object, the working-classes.
\end{abstract}

Key words: The thematic of labor in Brazilian university. Sociology of Sociology. Social history of a generation of labor sociologists. Reflexive ethnography of those who study employees.

\section{Plan D'Une histoire SOCIAle De LA PREMière GÉNÉRATION DES SOCIOLOGUES DU TRAVAIL ET DES TRAVAILLEURS AU BRÉSIL}

RÉSUMÉ: L'article annonce des questions qui guident la recherche en cours, telles que: les rapports individuels des premiers sociologues du travail avec les groupes hégémoniques à l'intérieur de la sociologie universitaire; leur intégration à d'autres instituts ou départements où la sociologie offre ses cadres; l'incidence de sanctions politiques qui ont eu pour effet d'interrompre ou de dévier leur carrière; les probabilités d'exposition à la circulation internationale des idées par le biais de voyages à l'extérieur, ou l'appartenance à des réseaux internationaux; et finalement leur exposition à la circulation des idées entre les classes sociales, en particulier par rapport à leur objet d' étude, la classe ouvrière.

Mots-clés: L'université et le thème du travail au Brésil. Sociologie de la Sociologie. Histoire sociale d'une génération de sociologues du travail. L'ethnografie réfléxive des chercheurs qui étudient les travailleurs.

A sociologia do trabalho brasileira, pela forma com que ela própria se apresenta no fim dos anos de 1960, aparece aos olhos dos observadores como o produto de um pensamento de escola, constituído em torno da Faculdade de Filosofia da Universidade de São Paulo (e, mais especificamente, em relação à cadeira de Sociologia I dirigida por Florestan Fernandes). Todos os indícios que derivam do exame da literatura levam a formular esta conclusão. ${ }^{1}$ As marcas exteriores às obras oferecem uma boa ilustração: são poucas as editoras; observa-se uma forte concentração numa coleção; os trabalhos são publicados num período relativamente curto de tempo, como se as obras tivessem sido fruto de um trabalho conjunto; a utilização de um número limitado de apresentadores; mestres e colegas que fazem prefácios e apresentações circulares (um autor faz o prefácio de um livro de outro autor que fará a apresentação de um livro do seu prefaciador, e assim por diante); 
tudo contribui para passar a ideia de um grupo pequeno e fortemente coeso que faz conhecer sua produção. Esses efeitos fizeram-se sentir também no interior dos livros: a progressiva intercitação, a expressão de temáticas comuns e, inclusive, de "teses" comuns. ${ }^{2}$ De certa forma, estas obras podem ser consideradas como sendo parte da "escola de sociologia de São Paulo". ${ }^{3}$

No entanto, observando-se com maior cuidado, pode-se constatar que a maior parte dos autores das obras "clássicas" sobre trabalho e sindicalismo ocupa posições inicialmente marginais ao centro hegemônico desta escola sociológica, que os incorpora nos seus meios de publicação. Há um efeito de pertencimento retrospectivo que, no momento mesmo da produção das pesquisas, só existe de uma forma mediatizada.

A intenção desta pesquisa é aprofundar, por um lado, a análise das diferenças nas trajetórias destes sociólogos, considerando que mais do que uma "escola de pensamento", trata-se de um "pensamento de escola", na medida em que todos eles passaram ou por alguma das duas cadeiras de sociologia da Universidade de São Paulo, ou pela Escola de Sociologia e Política. ${ }^{4}$ As relações individuais destes sociólogos com os grupos hegemônicos dentro da sociologia universitária; sua integração nos outros institutos ou departamentos aos quais a sociologia oferecia seus quadros; a incidência de sanções políticas que tiveram o efeito de interromper ou de desviar suas carreiras; as probabilidades de exposição à circulação internacional das ideias, através dos deslocamentos pessoais ao exterior ou por seu pertencimento a redes internacionais; assim como também sua exposição diferencial à circulação das ideias entre as classes sociais, em particular com relação ao seu próprio objeto de estudo, a classe operária;, estas são algumas das questões que deverão ser aprofundadas.

Por outro lado, trata-se de comparar a experiência e a produção desses sociólogos profissionais de São Paulo, com o que ocorria em outros centros de pensamento do país, em particular no Rio de Janeiro. Trata-se, também, de analisar a circulação entre os grupos de pesquisadores de São Paulo e os do Rio de Janeiro (cf., por exemplo, as relações entre F. Fernandes, O. Nogueira, ou J. R. Brandão Lopes e a equipe do Centro Brasileiro de Pesquisas Educacionais [CBPE] do Rio de Janeiro), sem abstrair a presença de outros centros. ${ }^{6}$

As análises propostas pelos críticos e as resenhas bibliográficas que focalizam os estudos sobre trabalhadores estão centradas sobre as temáticas, os resultados, os debates, em suma, sobre os conteúdos das obras produzidas a respeito da classe trabalhadora brasileira. ${ }^{7}$ Sem deixar de reconhecer a pertinência destas análises, o que aqui se propõe refere-se menos aos objetos das pesquisas que à relação dos pesquisadores com seus objetos de estudo; isto é, tem menos a ver com os textos e mais a ver com os contextos. Ora, se os contextos das obras quase não são importados 
junto com as obras na circulação das ideias entre as nações, também acontece que estes contextos se perdem entre uma e outra geração no interior das próprias nações: este é o caso do desenvolvimento desta questão no Brasil, especialmente alterado pelos efeitos da intervenção do campo político sobre o campo intelectual e sobre a universidade.

Pode-se admitir para maior comodidade que esta literatura seja apresentada como associada a diferentes "fases": aquela anterior a 1964 (na maior parte dos casos, pesquisas iniciadas nos anos de 1950 e publicadas entre 1964 e 1970), o período 1972-78, quando são feitas as primeiras rupturas com as análises anteriores, e o período da produção mais massiva das florescentes pós-graduações, a partir do fim dos anos de 1970. Neste projeto dar-se-á uma atenção particular ao primeiro período: ele é especialmente importante não somente para neutralizar os efeitos do anacronismo provocado pelas mudanças operadas pelo golpe de Estado de 1964 (data que atravessa todos os campos e os transforma), mas também por causa das propriedades de gênese que ele contém - esse complexo trabalho social de construção de novos profissionais, posições sociais e apreciações performativas sobre as classes populares. As relações entre os primeiros estudiosos do sindicalismo, divididos entre o direito, a sociologia e o Ministério de Trabalho; a posição e a trajetória dos primeiros sociólogos do trabalho na universidade; as relações entre estes sociólogos, o sindicalismo e o movimento operário; todas elas são mediações constitutivas entre intelectuais e classes populares - atravessando o Estado, o campo de produção cultural (especialmente a universidade) e o campo das associações das classes populares. Estas relações - como a própria produção de problemáticas sobre o trabalho e os trabalhadores - têm tido, também, o efeito de contribuir para a construção destes últimos como grupo social.

O primeiro período ainda apresenta a vantagem de mostrar com clareza as relações entre a temática relativa ao trabalho e as temáticas e formas dominantes de trabalhar nas ciências sociais brasileiras, revelando, também, o processo de circulação das ideias que então teve lugar.

\section{Indicações a respeito da trajetória dos autores escolhidos}

A análise da produção desse período deve tomar como ponto de partida a trajetória - pessoal, profissional, institucional, política - de cinco estudiosos do trabalho e do sindicalismo no Brasil: Aziz Simão, Evaristo de Moraes Filho, José Albertino Rodrigues, Leôncio Martins Rodrigues e Juarez Brandão Lopes.

L. M. Rodrigues começou sua carreira de pesquisador no projeto "A empresa industrial em São Paulo", elaborado em 1962 por Florestan Fernandes com 
a colaboração de Fernando Henrique Cardoso e Octávio Ianni. Ele foi um dos principais beneficiários desse projeto, relacionado ao "núcleo" sociológico constituído em torno de Florestan, na cadeira de Sociologia I da USP, e interrompido por causa da repressão contra os professores e pesquisadores da universidade no período posterior a 1964, o que provocou a dispersão da equipe: ele foi o único que publicou dois livros a partir de sua participação nesse projeto (cf. nota 2), um sobre os conflitos sindicais (sua dissertação de mestrado) e o outro sobre as "atitudes" dos operários de uma indústria de automóveis, coletadas através de questionários (sua tese de doutorado).

Azis Simão, nascido em 1912, também foi professor da USP nos anos de 1950 e 60, mas era ligado à cadeira de Sociologia II, dirigida por Fernando de Azevedo (que era tida como rival da cadeira de Sociologia I), onde ingressou como assistente através de Antonio Candido (o qual era o primeiro assistente desta cadeira). No entanto, Simão teve uma entrada tardia na universidade devido à sua militância sindical nos anos de 1930 e no Partido Socialista. ${ }^{8}$ Uma outra razão para este atraso foi sua progressiva cegueira; no começo, durante o período ditatorial de Vargas, ele entrou na faculdade como estudante auditor livre e fez um percurso lento, devido a sua deficiência visual. Foi recrutado na carreira universitária em virtude de suas persistentes qualidades intelectuais, ainda que frente a sua adversidade física, e também devido ao seu conhecimento direto do mundo operário. Desde o fim dos anos de 1940, Simão realizou uma longa pesquisa sobre as transformações sindicais operadas pela ação do Estado central após os anos 30, aproveitando sua possibilidade de ter um contato privilegiado com informantes sindicais e acesso a seus arquivos privados. Esta pesquisa resultou, em 1964, na defesa de sua tese de livre-docência sobre as relações entre sindicato e Estado e, em 1965, em sua publicação. Simão foi o primeiro, no interior da universidade, a fazer estudos sociológicos sobre os operários industriais. ${ }^{9}$

J. R. Brandão Lopes (nascido em 1925) teve em comum com Florestan Fernandes sua formação de mestrado na Escola Livre de Sociologia e Política (ESP), mas diferentemente de seu futuro orientador de doutorado, Brandão Lopes fez ali também a graduação. Adquiriu a experiência na pesquisa empírica dos community studies orientados por Donald Pierson e, no fim do curso, obteve uma bolsa para fazer estudos de pós-graduação na Universidade de Chicago, onde apresentou uma dissertação de mestrado, sob a orientação de Louis Wirth, que tinha como objeto o estudo das relações raciais nas escolas daquela cidade americana. Antes de voltar ao país, ele preparou seu projeto de doutorado, comparando duas cidades industriais brasileiras. Já no Brasil, foi convidado para trabalhar no Instituto de Economia e Administração da USP, que estava sendo dirigido por seu antigo professor da ESP, o antropólogo M. W. Vieira da Cunha, que também havia estudado em Chicago. Seu 
recrutamento revela a importante contribuição dos quadros formados em Sociologia (na USP ou na ESP) para a formação da Faculdade de Economia da USP, que se constituiu depois da Faculdade de Filosofia. Brandão Lopes também participou da seção paulista do projeto de pesquisa sobre "cidades-laboratório", organizado pelo Centro Brasileiro de Pesquisas Educacionais (CBPE), que era dirigido desde o Rio de Janeiro pelo etnólogo Darcy Ribeiro (outro antigo aluno da ELSP). Esse projeto permitiu-lhe levar adiante duas pesquisas: a primeira, sobre uma usina metalúrgica em São Paulo, na qual estudou as relações industriais entre os operários e a administração; e a outra (uma reformulação de seu projeto de doutorado elaborado em Chicago), sobre duas cidades industriais têxteis no interior do estado de Minas Gerais. ${ }^{10}$

Assim, diferentemente dos estudos industriais realizados pelo grupo do Centro de Sociologia Industrial e do Trabalho (Cesit-USP) da Cadeira I de Sociologia da USP - fortemente apoiados em dados coletados por meio de questionários - os trabalhos de Brandão Lopes tiveram a forte marca empírica da observação direta, própria da tradição dos estudos sociológico-antropológicos de comunidade, desenvolvidos pelos pesquisadores da ESP e por seus mestres de Chicago, e retomados, no Rio, pela equipe do CBPE. ${ }^{11}$ Essas qualidades contribuíram para manter a atualidade dos estudos de Brandão Lopes, quando as pesquisas sobre estas questões foram revigoradas na segunda metade dos anos de 1970. Seu longo percurso até o Departamento de Ciências Sociais só terminou com a idade de 50 anos: depois de estar isolado na Faculdade de Economia, em 1962 ele mudou-se para a Faculdade de Arquitetura e Urbanismo, onde foi titular; foi somente em 1974 que passou ao reorganizado Departamento de Ciências Políticas.

Se a trajetória de Brandão Lopes é em boa medida marginal à sociologia institucional, a de J. A. Rodrigues é marginal à universidade. Paradoxalmente, seu reconhecimento universitário se fez fora de um trabalho estritamente acadêmico. Originário de uma família numerosa, cujo pai era imigrante português, e morando no interior do estado de São Paulo, Rodrigues teve a mesma experiência de pesquisa empírica sociológico-etnológica na ESP. Foi atraído pela história econômica por Sérgio Buarque de Holanda (professor da ESP) e por Caio Prado Jr. (historiador marxista externo à universidade). Rodrigues foi recrutado pelo Instituto de Economia como assistente da cadeira de História Econômica, tendo um projeto de pesquisa sobre trabalho livre na sociedade colonial. Mas sua trajetória até a sociologia universitária e sua integração ao grupo de autores editados pela coleção de F.H. Cardoso (cf. nota 1) passaram por um longo percurso por fora da universidade, onde ele finalmente chegou a ser conhecido pelo fato de ter inventado, nos anos de 1950, a posição social de conselheiro sindical de formação universitária, ou, mais geralmente, a posição de técnico a serviço das classes populares (posição esta que se generalizou desde os anos 80 , junto aos centros e associações civis "ao serviço do movimento 
popular", que atualmente pertencem ao universo das denominadas ONGs). Para realizar esta invenção, Rodrigues teve que passar por uma dupla exclusão: da universidade, depois de um conflito com o titular da cadeira, e do Partido Comunista, onde terminou uma militância, depois dos acontecimentos internacionais de 1956, iniciada desde 1951. Desempregado, ele conseguiu capitalizar, na relação com os dirigentes sindicais, ao mesmo tempo sua formação universitária e seus conhecimentos de jovem professor militante de esquerda, e propôs um plano de atividades para o novo Departamento Intersindical de Estudos Estatísticos e Sócio-Econômicos (Dieese), recém-criado por um grupo de sindicatos paulistas em 1955. Rodrigues foi diretor técnico do Dieese entre 1956 e 1962, tendo voltado ao cargo entre 1965 e 1966 para recriá-lo nas condições adversas provocadas pelo golpe de Estado de 1964. Ele investiu seu habitus e sua técnica universitários, garantindo uma estabilidade técnica e uma independência vis à vis das diferentes tendências políticas e sindicais. Sua volta à universidade (à nova Universidade de Brasília, onde foi nomeado por indicação de Florestan Fernandes a Darcy Ribeiro e onde lecionou entre 1962 e 1965) foi interrompida pela repressão militar. Depois de reestruturar o Dieese, em 1965, ele saiu do país e fez um doutorado na França com Pierre Vilar, sobre a história das corporações artesanais na Lisboa do século XVI, depois de reaproximar-se de seu projeto inicial do estudo do trabalho livre no Brasil colonial. Após uma temporada em Portugal, defendeu sua tese em Paris no mês de maio de 1968. Na sua volta ao Brasil, trabalhou em empresas de consultoria no período de maior dificuldade de acesso à universidade pública no regime militar, antes de tornar-se professor de universidades do interior do estado de São Paulo. Durante todo esse período, permaneceu como consultor das equipes do Dieese.

Evaristo de Moraes Filho é o autor do livro pioneiro O problema do Sindicato Único no Brasil, seus fundamentos sociológicos (Rio de Janeiro: s.n., 1952), republicado em São Paulo pela editora Alfa-Omega, em 1978. Trata-se da primeira crítica jurídica e sociológica da estrutura sindical corporativista, realizada por alguém que, tendo feito uma carreira como procurador do Ministério do Trabalho, depois de ser jovem secretário da comissão mista de conciliação nos anos de 1930, conheceu desde o interior do aparelho de Estado até as limitações à autonomia associativa dos trabalhadores. Moraes Filho fez sua carreira, ao mesmo tempo, nas faculdades de Direito e de Filosofia da antiga Universidade do Brasil, sendo o primeiro diretor do Instituto de Ciências Sociais da UB, depois UFRJ (experiência interinstitucional original e precursora da pesquisa de campo mais especificamente sociológica no Rio de Janeiro), entre 1966 e 1968, até ser cassado da cadeira pelo regime militar, em 1969. Ele fez uma transição entre, de um lado, os "pensadores sociais" de formação ou prática jurídica, como Oliveira Vianna, seu pai Evaristo de Moraes, Joaquim Pimenta, ou ainda os funcionários (menos conhecidos do público) do Ministério de Trabalho que 
escreveram relatórios e pareceres jurídicos, tendo um conhecimento prático dos fenômenos e conflitos sindicais; e, de outro lado, os sociólogos do trabalho de São Paulo. Paradoxalmente, sua obra foi em grande parte ignorada na literatura subsequente de sociologia do trabalho que se constitui em São Paulo. Voltada para a construção universitária pioneira da sociologia como centro hegemônico das áreas de Ciências Humanas na Universidade de São Paulo, a "Escola Paulista de Sociologia" era um ambiente propício para o esquecimento de contribuições que não estivessem envolvidas no esforço implícito de autonomização da disciplina. Uma contribuição produzida assim na Faculdade de Direito, de cuja matriz aquela escola pretendia distanciar-se naquele momento, passou despercebida pelos autores, lidando com a temática do trabalho e do sindicalismo. ${ }^{12}$ Não é por acaso que a obra de Evaristo é resgatada por José Albertino Rodrigues, sensibilizado por sua observação participante do sindicalismo pelo viés da instituição técnica de assessoria aos sindicatos, por ele mesmo construída nos anos de 1950, o Dieese, e que fez levantamentos na Biblioteca Nacional e no Ministério do Trabalho, no Rio de Janeiro, para a pesquisa que resultou na obra Sindicato e desenvolvimento no Brasil, de 1968. De fato, a recepção de $O$ problema do Sindicato Único está relacionada à atualização das conjunturas políticas favoráveis à crítica da estrutura sindical brasileira: em 1962, quando do fortalecimento do movimento sindical e da publicação de livros sobre as suas lutas no passado, a obra teve uma repercussão maior do que no seu lançamento dez anos antes (em edição limitada, sem editora), quando então se relaxava timidamente o controle rígido prevalecente sobre os sindicatos de trabalhadores, por ocasião do segundo mandato presidencial de Getúlio Vargas, eleito em $1950 .{ }^{13}$ Em 1978, com o surgimento do movimento social tendo por centro a atuação sindical no ABC paulista e em São Paulo, no declínio do regime militar, O problema do Sindicato Único teve sua segunda edição publicada pela editora Alfa-Ômega, prefaciada por Paulo Sergio Pinheiro, então estudioso da sociologia do trabalho na Universidade de Campinas.

Esses cinco autores, necessariamente, serão postos em relação com seus pares do campo das Ciências Sociais de sua época, assim como de gerações mais jovens que lhes sucedem e influenciam a apropriação de sua obra. ${ }^{14}$

A respeito das contribuições de autores e instituições internacionais, permitese a digressão que se segue. Os estudos sobre trabalhadores urbano-industriais aqui privilegiados devem ser situados relativamente à construção dos temas dominantes nas Ciências Sociais brasileiras, e também do aporte das contribuições estrangeiras: desde as relações raciais entre negros e brancos (cf. a tese de doutorado de D. Pierson em Chicago, cf. a pesquisa de R. Bastide e F. Fernandes, financiada por A. Métraux desde a Unesco), até os estudos do trabalho feitos pelo viés da industrialização e do desenvolvimento econômico (cf. a importância das organizações latino-americanas da ONU). A propósito, a importância da hegemonia dos estudos socioeconômicos 
sobre a temática do desenvolvimento é tão grande entre os anos de 1950 e 70 que tudo se passa como se os novos temas relacionados à classe operária fossem confrontados somente aos antigos temas dominantes da problemática desenvolvimentista, e fossem esquecidos os temas anteriormente dominantes das relações raciais e da escravidão, como se eles não tivessem nenhuma relação com a temática dos trabalhadores ou das classes populares. Somente depois dos anos de 1980 é que estes dois aspectos da vida das classes populares vieram a ser colocados em relação, junto à ascensão dos movimentos pela cidadania dos negros ou aos financiamentos das agências internacionais que, como a Fundação Ford, estimularam os estudos sobre os negros. De uma forma mais geral, torna-se necessário identificar os intercâmbios internacionais, pelo menos entre as Ciências Sociais estadunidense e francesa com as Ciências Sociais brasileiras.

\section{Considerações finais}

O corpus empírico inicial que serviu de base à formulação deste projeto se constituiu não somente dos traços materiais deixados pelas obras dos autores estudados, mas também e principalmente por entrevistas com eles realizadas no início dos anos de 1990. Tais entrevistas forneceram indicações sobre as propriedades comuns aos autores e também sobre suas diferenças internas. Os dois mais velhos, Azis Simão e Evaristo de Moraes Filho tiveram experiências com o mundo do trabalho no início de suas trajetórias. Azis, que fez estudos de farmácia, conviveu com sindicalistas da cidade de São Paulo no início dos anos de 1930, formados no período anterior à legislação trabalhista sistemática inaugurada naquela mesma década, através de sua participação como professor de Ciências na formação continuada de adultos no sindicato dos gráficos. O segundo, graduado na Faculdade Nacional de Direito no Rio de Janeiro, iniciou sua carreira jurídica como secretário das comissões de conciliação entre patrões e trabalhadores no recém-fundado Ministério do Trabalho. A sensibilidade adquirida por ambos através da observação direta dos sindicatos, seja do ponto de vista do sindicato operário, seja da perspectiva da conciliação e da mediação dos conflitos entre patrões e trabalhadores, pôde incorporar-se à sua produção sociológica posterior, presente nas entrelinhas de seus respectivos livros seminais - $O$ problema do Sindicato Único, de Evaristo (1952), e Sindicato e Estado, de Azis (1966). No entanto, aquela sensibilidade só poderia ser recuperada muitos anos depois de publicados os livros, quando a valorização mais tardia da perspectiva antropológica, adquirida pelas pós-graduações desta área de conhecimento pôde produzir leitores ativos interessados numa etnografia histórica. Por outro lado, na geração mais nova que se seguiu, profissionalizada no pós-guerra na sociologia universitária, três autores mostram o espectro de possibilidades diferenciadas de trajetórias a partir de sua 
formação universitária comum nas Ciências Sociais dos anos de 1950. Juarez teve sua formação acadêmica na Escola de Sociologia e Política, marcada pela presença de Donald Pierson, complementada por um período na Sociologia da Universidade de Chicago. De volta ao Brasil, reuniu as qualidades do aprendizado das perspectivas ao mesmo tempo sociológicas e antropológicas que caracterizavam a tradição daquela primeira escola sociológica estadunidense para fazer uma pesquisa de fôlego em duas cidades industriais, em Minas Gerais, no livro Crise do Brasil arcaico, cujas contribuições permanecem válidas ao longo do tempo para novas gerações. Foi recrutado por seu ex-professor na Escola de Sociologia e Política, Mario Wagner Vieira da Cunha, também ele ex-aluno da Sociologia e Antropologia de Chicago, para a Faculdade de Economia e Administração, por ele dirigida. Embora pareça fora do comum que esta última faculdade seja dirigida por um sociólogo-antropólogo, tal fato não se distancia do que ocorre na inflexão da carreira de antropólogos como Lloyd Warner e William Foote Whyte, em direção à sociologia industrial nos Institutos de Relações Humanas criados nas universidades de Harvard, Yale e Chicago. Da economia e administração, Juarez passou ainda pela Faculdade de Arquitetura e Urbanismo antes de se estabelecer na Ciência Política da USP, em meados dos anos de 1970.

Já o colega três anos mais novo de Juarez na Escola de Sociologia e Política, José Albertino Rodrigues, seguiu inicialmente o caminho da História Econômica entre outras possibilidades de sua formação multidisciplinar naquela escola. Mas as contradições da forma de dominação catedrático-assistente da universidade dos anos de 1950 seriam apropriadas por Albertino numa construção institucional extrauniversitária até então inusitada, a sua contribuição decisiva à assessoria técnica dos sindicatos de trabalhadores. Tal experiência é incorporada nas entrelinhas de seu livro Sindicato e desenvolvimento no Brasil, retomando a sensibilidade manifestada nas vivências de Azis e Evaristo.

Leôncio Martins Rodrigues, que teve sua entrada na Sociologia da USP retardada em alguns anos, em virtude de suas atividades militantes no movimento estudantil, beneficiou-se diretamente da escola sociológica hegemônica na USP, aquela constituída pela cátedra de Sociologia I, dirigida por Florestan Fernandes, auxiliada por seus dois principais assistentes, Fernando Henrique Cardoso e Octavio Ianni. No Centro de Estudos de Sociologia Industrial e do Trabalho (Cesit), criado por aquela cátedra, Leôncio fez suas teses sobre conflitos industriais e sindicalismo, bem como sobre industrialização e atitudes operárias. Permaneceu fiel a uma orientação de pesquisas por questionário e a uma renovação de estudos sobre sindicalismo ao longo do tempo, numa perspectiva sociológica mais estrita.

Passado o tempo das primeiras entrevistas realizadas com estes cinco autores no início dos anos de 1990, o corpus empírico do presente projeto aumentou significativamente, embora de forma desigual entre eles. De Azis e Albertino poucos 
materiais suplementares foram localizados após a morte de ambos. Por outro lado, nos últimos anos foi constituído o portal de Evaristo de Moraes Filho no Arquivo do Movimento Operário do Rio de Janeiro (IFCS-UFRJ) com suas publicações e muitas informações sistematizadas; multiplicaram-se as entrevistas memorialísticas de Juarez e Leôncio ao longo do tempo. Também aumentou significativamente a produção memorialística de outros autores contemporâneos aos cinco privilegiados no projeto, que com eles mantiveram relações estruturadas no campo temático de estudos sobre o trabalho (ver nota 14). O esforço de reconstituição cruzada das relações entre esses diferentes autores e também da maneira como foram apropriados pelas gerações seguintes poderão trazer resultados para o entendimento da problemática sobre o trabalho e os trabalhadores ao longo do tempo, com seus silêncios e retornos à atualidade científica.

\section{Notas}

1. Cf., especialmente, Lopes (1964, 1967); Pereira (1965); Simão (1966); Rodrigues, (1966, 1971); Rodrigues (1968). Todos os livros da editora Difusão Européia do Livro pertencem à coleção "Corpo e Alma do Brasil", dirigida por F. H. Cardoso, que havia sido primeiro assistente de Florestan Fernandes. Cf. também, em Sociologie du Travail, os artigos de Lopes (1961); Cardoso (1961); Simão (1961); Touraine (1961).

2. Algumas destas temáticas ou "teses" comuns eram: a "heteronomia" da classe operária e do sindicalismo brasileiro; a oposição entre dois períodos históricos da classe operária: o período anterior a 1930, com os operários de origem estrangeira (imigrantes italianos, portugueses, espanhóis) e as associações autônomas, e o período posterior a 1930, com os operários de origem rural e os sindicatos "heterônomos"; a tese da origem rural da classe operária depois de 1930; a ausência de consciência profissional e de classe que beneficia o desejo de mobilidade em relação ao retorno ao campesinato ou ao acesso ao pequeno comércio.

3. Esta é uma denominação corrente da produção e dos grupos de sociólogos de São Paulo, exercendo um efeito unificador e redutor, geralmente utilizado com objetivos de síntese. Cf., por exemplo, o ensaio de Morse (1992). Ver também Arruda (1995). Cf. também o emprego dessa expressão em Leite Lopes (1991).

4. Sobre a origem da Escola de Sociologia e Política e sobre suas relações com a sociologia da Universidade de São Paulo, cf. Limongi (1989) e Corrêa (1987).

5. Azis Simão teve um conhecimento direto do movimento operário dos anos de 1930, o que marcou toda sua carreira e sua obra universitária posterior. José Albertino Rodrigues investiu seu conhecimento, sua ética e seu habitus universitário, prematuramente interrompidos, para inventar, nos anos de 1950, a posição de conselheiro sindical de formação universitária.

6. Para tanto, a ideia é recuperar a trajetória de Evaristo de Moraes Filho, figura exemplar dos sociólogos de uma formação anterior, divididos entre a sociologia e o direito do trabalho, entre o conhecimento acadêmico e o campo burocrático do Estado (cf. Leite Lopes, 2005). É importante fazer também um exercício de comparação com o que se passa em Pernambuco, então polo de pensamento social no Norte-Nordeste do país, onde o prestígio da Faculdade de Direito e de pensadores que por ela passaram - e, depois, de Gilberto Freyre e sua obra - acabou por produzir instituições de ensino e pesquisa como a Faculdade de Ciências Sociais do Recife e o Instituto Joaquim Nabuco, que coexistiram com as instituições, as iniciativas de pesquisa e os pesquisadores do Rio e de São Paulo nos anos de 1940, 50 e 60. A recuperação da maneira como a problemática do trabalho e dos trabalhadores é por aí tratada, desde o trabalho agroindustrial, desde as controvérsias em torno do 
mucambo e desde a presença importante, mas pouco tematizada, de trabalhadores e vilas operárias têxteis, poderia salientar esses aspectos menos visíveis daquela produção e servir ao mesmo tempo de comparação com o que se passa no eixo "central" Rio-São Paulo. Isto pode ser recuperado através de escritos e depoimentos a serem recolhidos de Edson Nery da Fonseca, Manuel Correia de Andrade, Heraldo Souto Maior, Francisco de Oliveira, Roberto Motta e Silke Weber (ou em artigos de Antonio Motta e Eliane Veras).

7. Cf. Brandt (1967); Queiroz (1972); Simão (1972); Rodrigues (1972); Rodrigues \& Munhoz (1974); Pinheiro (1975); Werneck Vianna (1978, 1984); Paoli \& Sader (1986).

8. Nascido numa família de comerciantes de origem sírio-libanesa, Simão conheceu sindicalistas de São Paulo pela via do seu trabalho como jornalista, e pela intermediação de seu irmão mais velho, que era médico no sindicato dos gráficos. Tendo estudado farmácia, Simão deu cursos noturnos de ciências naturais neste sindicato e fez amizade com os principais dirigentes sindicais de São Paulo dos anos de 1930, os quais ele teve oportunidade de conhecer antes do domínio estatal sobre os sindicatos que se acentuou em 1937.

9. É importante tomar-se aqui o depoimento de Heloísa Martins, que foi orientada por Azis Simão e ela própria produtora deste campo de estudos.

10. Estas pesquisas, realizadas respectivamente em 1955-56 e 1958, transformaram-se em dois livros, publicados em 1964 e 1967 (cf. nota 1). O último deles, Crise do Brasil arcaico, veio a ser sua tese de doutorado, defendida em 1966 sob a orientação de F. Fernandes, e que lhe permitiu obter o titulo sem fazer os cursos. É preciso observar que, antes mesmo do seu doutorado, Brandão Lopes já era professor substituto do titular da cadeira de "ciência da administração e estrutura das organizações econômicas", tendo um status universitário equivalente ao do próprio F. Fernandes. Daí em diante, a fama de seus estudos consolidou-se.

11. É importante aqui conferir o depoimento da antropóloga Maria Laís Mousinho Guidi, que trabalhou no CBPF desde o período em que Darcy Ribeiro foi diretor e acompanhou estas pesquisas, além de ter feito um balanço destes estudos entre o final dos anos de 1950 e início dos 60.

12. Assim, como assinala Evaristo no posfácio à segunda edição de seu livro, Azis Simão, autor de Sindicato e Estado, livro fundamental na temática, publicado em 1966, não cita O problema do sindicato único na sua bibliografia; em Conflito industrial e sindicalismo no Brasil, outro livro de referência, de Leôncio Martins Rodrigues, também de 1966, ele é citado de passagem. O livro de Azis Simão guarda características de sensibilização através da experiência direta com o sindicalismo de São Paulo dos anos de 1930 aos de 1950, que se assemelham às características comuns com o livro de Evaristo. O livro de Leôncio é fruto dos projetos coletivos formulados no Centro de Sociologia Industrial e do Trabalho, associado à cadeira I de Sociologia da USP, coordenados por Florestan Fernandes. Ambos os estudos fazem parte de um esforço considerável e fundamental das ciências sociais brasileiras entre os anos de 1950 e 1960, fazendo de São Paulo um laboratório essencial para o entendimento das questões sociológicas colocadas pelo Brasil.

13. No início dos anos de 1960, Evaristo esteve em ascensão no campo das ciências sociais, com sua participação na direção do Instituto de Ciências Sociais da Universidade do Brasil. Em 1962, foi vice-presidente da Sociedade Brasileira de Sociologia, tendo por presidente Florestan Fernandes, como informa em entrevista, e em $1964 \mathrm{fez}$ parte da banca do concurso para professor titular de Fernandes na USP, examinando a tese da "Integração do negro na sociedade de classes". Em 1963, com base em sua notoriedade na área do direito do trabalho, onde O problema do sindicato único ocupa um importante lugar, é nomeado como autor e relator do anteprojeto de código do trabalho. Os anos posteriores a 1964 viriam interromper muito do que estava sendo feito nas ciências sociais em São Paulo e, em particular, no Rio de Janeiro.

14. Além dos já citados, é importante conferir os depoimentos de Francisco Weffort, que trabalhou na temática entre os anos de 1960 e 70, também na USP; Francisco de Oliveira, formado em Ciências Sociais em Recife e colaborador de Celso Furtado na Sudene, que se exilou em São Paulo no pós-64 e participou da renovação da temática desde o início dos anos de 1970, trabalhando no Cebrap; Heloísa Martins, já referida, que além de ter sido orientada por Azis Simão, trabalhou com J. Albertino no Dieese e lhe sucedeu durante um período dos anos 60 na direção técnica daquela instituição; 
Walter Barelli, economista indicado por Otávio Ianni ao Dieese, contemporâneo mais jovem de J. Albertino e que depois coordenou a instituição desde o início dos anos 70; Paul Singer, cuja trajetória de militância no Partido Socialista e na USP interliga biografias como as de Azis e as daqueles que participaram depois do Cebrap; Luiz Werneck Vianna, produtor dessa área temática desde os anos 70, tendo nesses anos frequentado o Cebrap e depois feito sua carreira no Rio de Janeiro; e outros a serem selecionados e entrevistados no decorrer da pesquisa. Além disso, há que se comparar com as recentes publicações e disponibilizações de dados a respeito desses autores como, por exemplo, as sessões de "Conversa com o Autor", da Anpocs (no caso de Juarez Brandão Lopes, Leôncio Martins Rodrigues e José de Souza Martins), a Biblioteca Virtual Evaristo de Moraes Filho (www.bvemf.ifcs.ufrj.br), o livro dos cientistas sociais em homenagem a Evaristo (ver Pessanha, Vilas-Bôas e Morel, 2005), o livro autobiográfico de Francisco de Oliveira, Noiva da revolução (2008), e assim por diante.

\section{Referências}

ARRUDA, M.A. A Sociologia no Brasil: Florestan Fernandes e a "escola paulista". In: MICELI, S. (Org.). História das Ciências Sociais no Brasil. São Paulo: Sumaré; Idesp; Fapesp, 1995. v. 2. p. 107-232.

BRANDT, V.C. Ouvriers et syndicats au Brésil. Sociologie du Travail, Paris,v. 9, n. 3, p. 352-361, 1967.

CARDOSO, F.H. Le prolétariat brésilien: situation et comportement social. Sociologie du Travail, Paris,v. 3, n. 1, p. 52-65, 1961.

CORRÊA, M. (Org.). História da Antropologia no Brasil, 1930-1960, testemunhos de Emilio Willems e Donald Pierson. São Paulo: Vértice; Campinas: Unicamp, 1987. v. 1.

LEITE LOPES, J.S. Lectures savantes d'un syndicalisme paradoxal; la formation de la classe ouvrière brésilienne et le syndicat "officiel". Genèses, Paris, n. 3, p. 73-96, mars 1991.

LEITE LOPES, J.S. Entre o Direito e as Ciências Sociais: uma experiência central na história dos estudos sobre trabalho e trabalhadores no Brasil. In: PESSANHA, E.; VILLAS-BÔAS, G.; MOREL, R.L. (Org.). Evaristo de Moraes Filho, um intelectual humanista. Rio de Janeiro: Topbooks; ABL, 2005. p. 161-193.

LIMONGI, F. A Escola Livre de Sociologia e Política em São Paulo. In: MICELI, S. (Org.). História das Ciências Sociais no Brasil. São Paulo: Vértice, 1989. v.1, p. 217-233.

LOPES, J.R.B. Relations industrielles dans deux communautés brésiliennes. Sociologie du Travail, Paris, v. 3, n. 1, p.18-33, 1961.

LOPES, J.R.B. Sociedade industrial no Brasil. São Paulo: Difusão Européia do Livro, 1964.

LOPES, J.R.B. Crise do Brasil arcaico. São Paulo: Difusão Européia do Livro, 1967. 
MORAES FILHO, E. O problema do sindicato único no Brasil, seus fundamentos sociológicos. Rio de Janeiro: [s.n.], 1952. (2.ed. São Paulo: Alfa-Omega, 1978).

MORSE, R. Economia manchesteriana e sociologia paulista. In: MORSE, R. A volta de Mcluhanaíma. São Paulo: Cia. das Letras, 1992.

OLIVEIRA, F. Noiva da revolução: elegia para uma re(li)gião. São Paulo: Boitempo, 2008.

PAOLI, M.C.; SADER, É. Sobre "classes populares" no pensamento sociológico brasileiro. In: CARDOSO, R. (Org.). A aventura antropológica. Rio de Janeiro: Paz \& Terra, 1986. p. 39-68.

PEREIRA, L. Trabalho e desenvolvimento no Brasil. São Paulo: Difusão Européia do Livro, 1965.

PESSANHA, E.; VILLAS-BÔAS, G.; MOREL, R.L. (Org.). Evaristo de Moraes Filho, um intelectual humanista. Rio de Janeiro: Topbooks; ABL, 2005.

PINHEIRO, P.S. Trabalho industrial no Brasil: uma revisão. Estudos Cebrap, São Paulo, n. 14, p. 119-131, out./dez. 1975.

QUEIROZ, M.I.P. Achegas para a organização de uma bibliografia de Sociologia Industrial no Brasil. In: ENCONTRO INTERNACIONAL DE ESTUDOS BRASILEIROS, 1971, São Paulo. Anais do Encontro Internacional de Estudos Brasileiros e 1. Seminário de Estudos Brasileiros. São Paulo: IEB, 1972. v. 1, p. 130-145.

RODRIGUES, J.A. Sindicato e desenvolvimento no Brasil. São Paulo: Difusão Européia do Livro, 1968.

RODRIGUES, L.M. Conflito industrial e sindicalismo no Brasil. São Paulo: Difusão Européia do Livro, 1966.

RODRIGUES, L.M. Industrialização e atitudes operárias. São Paulo: Brasiliense, 1971.

RODRIGUES, L.M. Bibliografia sobre o sindicalismo e os trabalhadores industriais no Brasil; notas para um esquema explicativo. In: ENCONTRO INTERNACIONAL DE ESTUDOS BRASILEIROS, 1971, São Paulo. Anais do Encontro Internacional de Estudos Brasileiros e 1. Seminário de Estudos Brasileiros. São Paulo: IEB, 1972. v. 2, p. 157-183.

RODRIGUES, L.M.; MUNHOZ, F.A. Bibliografia sobre trabalhadores e sindicatos no Brasil. Estudos Cebrap, São Paulo, n. 7, p. 151-171, jan./mar. 1974.

SIMÃO, A. Sindicato e Estado; suas relações na formação do proletariado. São Paulo: Dominus; Edusp, 1966. 
SIMÃO, A. Industrialisation et syndicalisme au Brésil. Sociologie du Travail, Paris, n. 1, p. 66-76, 1961.

SIMÃO, A. Informação sobre o sindicalismo e a sociologia do sindicato no Brasil. In: ENCONTRO INTERNACIONAL DE ESTUDOS BRASILEIROS, 1971, São Paulo. Anais do Encontro Internacional de Estudos Brasileiros e 1. Seminário de Estudos Brasileiros. São Paulo: IEB, 1972. v. 2, p. 147-156.

TOURAINE, A. Industrialisation et conscience ouvrière à São Paulo. Sociologie du Travail, Paris, n. 1, p. 77-95, 1961.

WERNECK VIANNA, L. Estudos sobre sindicalismo e movimento operário: resenha de algumas tendências. Dados, Rio de Janeiro, vol. 3, p. 9-24, 1978.

WERNECK VIANNA, L. Atualizando uma bibliografia: "novo sindicalismo", cidadania e fábrica. Boletim Informativo e Bibliográfico de Ciências Sociais, Rio de Janeiro, vol. 17, p. 53-68, 1984.

Recebido em 17 de janeiro de 2012.

Aprovado em 15 de março de 2012. 